\title{
Effect of Angle of Attack Variation of Stern Foil on High-Speed Craft on Various Speed with Computational Fluid Dynamics Method
}

\author{
Haekal Dwiputera ${ }^{1}$, Naufal Yudha Prawira ${ }^{1}$, Mohamad Arif Andira², Muhammad Arif \\ Budiyanto ${ }^{1 *}$ \\ ${ }^{1}$ Naval Architecture and Marine Engineering, Department of Mechanical Engineering, Faculty of \\ Engineering, Universitas Indonesia, Kampus UI Depok, Depok 16424, Indonesia \\ 2PT. CCIT Group Indonesia, Jl. HM Usman No. 22 A Depok, 16425, Indonesia
}

\begin{abstract}
The development of high-speed craft technology for both the commercial sector and the military has grown rapidly in recent times. Optimizing recent inventions is one step toward realizing advanced ship technology. An element that affects efficiency is the effect on the hydrodynamics of the ship by the addition of a stern foil. A stern foil is an underwater hydrofoil that is mounted on the back of a ship to produce lift and additional thrust when the ship is in motion, impacting the trim and wet surface area of the ship and thus reducing drag. This study aims to determine the effect of the angle of attack configuration of a stern foil experimenting with a one-meter ship model at varying angles of attack: $0^{\circ}, 1^{\circ}, 2^{\circ}$, and $5^{\circ}$, using the computational fluid dynamic method. The results of this study indicate that the use of a specific stern foil configuration is effective in reducing the drag of the ship by $9 \%-26 \%$ in the Froude number range $0.5-0.75$.
\end{abstract}

Keywords: Angle of attack; Drag reduction; High-speed craft; Stern foil

\section{Introduction}

The development of advanced ship technology is facilitated by optimizing recent inventions to achieve higher efficiency and superior performance. An element that affects efficiency is the hydrodynamics of the ship. To achieve a fuel-economic ship, an analysis is performed to improve hull efficiency by modifying the front or aft of the monohull. If the hull is modified from a monohull into a catamaran, it increases the payload capacity but simultaneously increases the resistance by almost four times (Samuel et al., 2015). The application of a hydrofoil is one of the solutions to this. The hydrofoil has been extensively used in the maritime world as stabilizers on commercial ships and submarines and maneuvers. A stern foil is an underwater hydrofoil that is installed aft of the ship to generate lift and additional thrust when the ship is in motion, impacting the trim and wet surface area of the ship. At relatively high speeds, a stern foil can reduce the total drag on the ship. This technology was invented by Van Oossanen in 1992 and was patented in 2002 (Uithof et al., 2016a). A hull vane reduces drag more effectively than other appendixes (by up to 32.4\%), and it effectively reduces pitch motion and wave resistance (Uithof et al., 2016b).

Several researchers have investigated the effect on ship resistance of varying the

*Corresponding author's email: arif@eng.ui.ac.id,, Tel.: + 62-21-7270032, Fax: +62-21-7270033 doi: 10.14716/ijtech.v11i7.4467 
number of foils and the position of the foil on the hull vane, with results indicating that a $50 \% \mathrm{~T}$ position variation reduces resistance by $20.135 \%$, with heaving reduced by $33 \%$, and pitching by $33 \%$ (Nugroho et al., 2017). There is a study that demonstrates that a singlefoil hull vane ship model with a foil position of $2 \% \mathrm{LWL}$ behind the ship and $60 \% \mathrm{~T}$ is the optimal model for reducing total drag to $27.278 \%$. However, for a ship in motion, the optimal heaving and pitching values for a single-foil hull vane ship model are 4\% LWL behind the ship and $60 \% \mathrm{~T}$, yielding a reduction of $8.86 \%$ in the heaving value and $6.44 \%$ in the pitching value (Assidiq et al., 2017). On a hydrofoil ship with a trimaran hull moving at a service speed of 20 knots and 30 knots, the optimal angle of attack is $30^{\circ}$ and $20^{\circ}$, respectively. At a service speed of 40 knots, the ship would have reached a stall condition where it has lost its lift (Suryadi and Arief, 2016). Another study shows that crew ships using stern foil have superior response amplitude operator (RAO) heave and RAO pitch motion characteristics than ships without stern foils (Suastika et al., 2016). In experiments and simulations, at optimal load (half of the full load condition) and Fr 1.1, a reduction in resistance of $22.3 \%$ and $23.3 \%$ is obtained with the application of a stern foil. Furthermore, with variations to the stern foil configuration $\left(0^{\circ}\right.$ to the $\mathrm{x}$-axis) in a simulation, the reduction in resistance was found to be $26.7 \%$ and occurred at Fr 0.9 (Budiyanto et al., 2020b). The most effective hull vane depth with a $2^{\circ}$ angle of attack is at $100 \% \mathrm{~T}$ (Afriansyah et al., 2019). A hull vane effectively reduces fuel consumption by up to $12.5 \%$ when $\mathrm{LOA}=\mathrm{L}+\mathrm{LHv}$ and has been shown to reduce annual fuel expenditure (Hagemeister et al., 2017). The hull vane also effectively damps ship motion (Bouckaert et al., 2016)

Compared to a bare hull, using a surface piercing hydrofoil reduces the total resistance to $38.53 \%$ and conserves $61.5 \%$ of the ship's effective horsepower (Azis et al., 2017). A study has demonstrated that aspect ratio, Froude number, and CL/CD affect the stall phenomenon on hydrofoil application (Dewi, 2017). The relation between the hydrofoil position and the center of gravity of the ship also affects the extent of the reduction in the resistance of the ship because the moment occurs when the ship is flying (Slamet and Suastika, 2012). Using a swept fully submerged foil is also effective for reducing the resistance of the ship (Agustian et al., 2017). Using a winged air induction pipe (WAIP) consisting of an angled hydrofoil effectively reduces drag by about $10 \%$ compared to a nonhydrofoil plate (Yanuar et al., 2020).

The addition of Grothues spoilers with NACA 6412 foil variations yields the most optimal results, reducing the total resistance at Fn 0.18 by $13.728 \%$, viscosity resistance by $5.712 \%$, and wave resistance by $34.29 \%$. Furthermore, the results of a wake friction analysis indicate that a Grothues spoiler model with the NACA 6412 foil variation is optimal for reducing the wake value, and at its service speed, the wake value is decreased by $1.0402 \%$ (Lubis et al., 2018). The addition of four Grothues spoilers with NACA 64098 foil variations is optimal for reducing resistance to $11.7 \%$, with viscosity resistance reduced by $5.31 \%$, and wave resistance by $27.17 \%$. The results of a wake friction analysis also show that the model with an NACA 64098 foil variation is optimal for reducing the wake value, with the wake value decreased by $1.75 \%$ at its service speed (Siagian et al., 2018).

Based on these research findings, the focus of this research is to determine the effect of variations in the angle of attack of a stern foil on high-speed craft by comparing the Froude number and ship resistance. This study investigates the effect of the application of a stern foil in a high-speed craft using the computational fluid dynamics method. The results of the simulation are compared with those of previous experiments to find the total ship resistance in each stern foil configuration and to determine the optimal condition of the stern foil via variations in the angle of attack and speed of the ship, represented by the Froude number. The contribution of this study is its usefulness for determining the effect of the angle of 
attack of the stern foil on ship resistance and as a basis for consideration in the simulation stage of similar cases.

\section{Methods}

\subsection{Ship Dimensions and Stern Foil Design}

The ship model used in this research is the Mark VI patrol vessel, which belongs to the high-speed craft category and has a slender body hull model. This ship is scaled with a ratio of $1: 25.8$, such that the model has the following dimensions: length of $1 \mathrm{~m}$, width of 0.2403 $\mathrm{m}$, draft of $0.0465 \mathrm{~m}$, and displacement of $3.25 \mathrm{~kg}$. The simulation was performed at speeds of $1.57 \mathrm{~m} / \mathrm{s}, 1.76 \mathrm{~m} / \mathrm{s}, 1.93 \mathrm{~m} / \mathrm{s}, 2.1 \mathrm{~m} / \mathrm{s}$, and $2.3 \mathrm{~m} / \mathrm{s}$, such that the ship meets the IMO regulations for the high-speed craft category. The stern foil profile used was the NACA 4412, with span dimensions following the transom width of the ship, $0.2 \mathrm{~m}$, and chord, $0.04 \mathrm{~m}$, as shown in Figure 1.

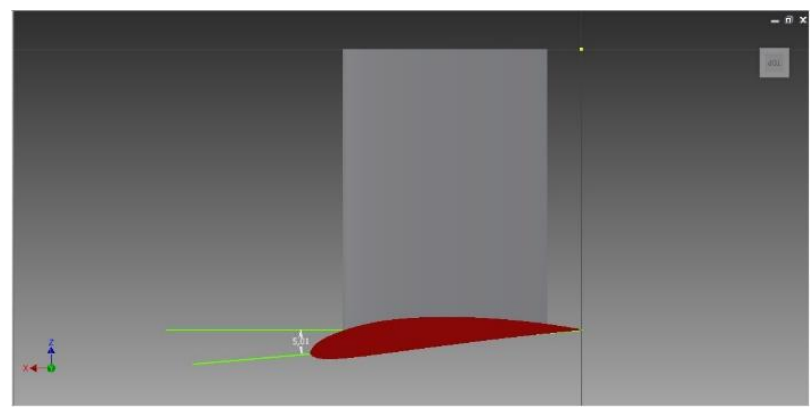

Figure $1 \mathrm{~A} 0^{\circ}$ view of the stern foil

The stern foil is installed at a depth of $100 \% \mathrm{~T}$, with strut dimensions of $0.06 \mathrm{~m}$ and 3D designs made with Autodesk Inventor, as shown in Figure 2. An attack angle of $0^{\circ}$ makes the stern foil parallel to the fluid flow passing through the transom area of the ship at a depth of $100 \% \mathrm{~T}$, which is $5.01^{\circ}$. Four variables are tested using this simulation method: an angle of attack of $0^{\circ}, 1^{\circ}, 2^{\circ}$, and $5^{\circ}$.

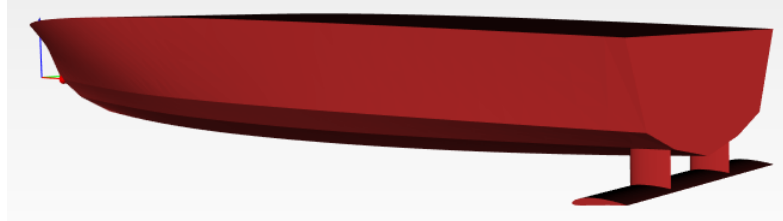

Figure 2 Ship and stern foil for the 3D design

\subsection{Boundary Conditions}

In this study, the simulation was performed using the computational fluid dynamics method via CFDSOF software (CCIT Group Indonesia, n.d.), developed by CFD software in Indonesia. To achieve the proper setup in the CFDSOF software, the first thing is to make geometry preparations by importing the ship design and foil stern separately. Ensure that the vessel is pointing toward the negative $\mathrm{x}$-axis such that fluid flows from the negative $\mathrm{x}$ axis to the positive x-axis. Subsequently, to capture the transition area between air and water, and to obtain a higher accuracy for the portion of the vessel exposed to water, a box called a refinement box is required. With the drawn geometry feature, we can make a refinement box of dimensions $12 \mathrm{~m} \times 6 \mathrm{~m} \times 0.5 \mathrm{~m}$. In CFDSOF, we need a box to represent a pool of water. The dimensions of this box are $13 \mathrm{~m} \times 7 \mathrm{~m} \times 6.5 \mathrm{~m}$, as shown in Figure 4 . This 
water box must overlap the refinement box. In this geometry preparation, there are four geometries: the ship, stern foil, refinement box, and the water box.

The next step is meshing. Meshing is the process of forming a model into cells that are taken into account when a computation is run. In ship geometry, the refinement level parameter assigned to the surface of the ship is a level 5 surface refinement. For stern foil geometry, the assigned surface refinement is level 7 because the stern foil has a complex shape and the water (fluid) passes through it and contacts its entire surface. Therefore, a higher level than that for the ship geometry is needed for the stern foil shape to be captured properly. In the refinement box, meshing is not enabled. However, it will be activated for refinement. The refinement region given in this box is level 2, with inside mode. The water box is not activated for meshing or refinement.

The next step is to create a closure box using the base mesh feature, with the dimensions $12 \mathrm{~m} \times 6 \mathrm{~m} \times 9 \mathrm{~m}$. This closure box will be activated for meshing with mesh distributions in the $\mathrm{x}, \mathrm{y}$, and $\mathrm{z}$ directions of 50,25 , and 38, respectively. In this base mesh feature, it is required to set the boundaries of each face on the box. In this case, $\mathrm{X}-$ is arranged as an inlet, $\mathrm{X}+\mathrm{s}$ an outlet and $\mathrm{Y}-, \mathrm{Y}+$, and $\mathrm{Z}$ as symmetry because at these faces, it is predicted that the characteristics of the fluid are the same as the characteristics of the fluid outside the wall, and $\mathrm{Z}+$ is set as the boundary representing air fluid. To successfully generate the mesh, the mesh location needs to be considered, such that the location points are outside the geometry of the ship and the foil stern. You need to check the mesh to make sure that the resulting mesh is okay. With these parameters, the number of cells produced is 357,646 .

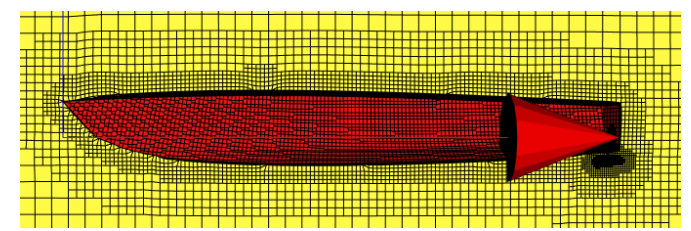

(a)

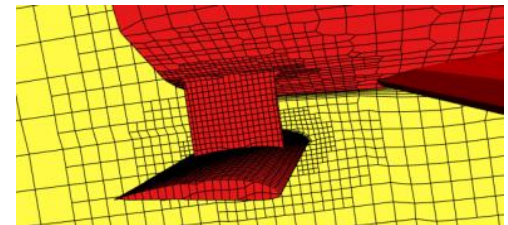

(b)

Figure 3 Mesh results: (a) Ship; and (b) Stern foil

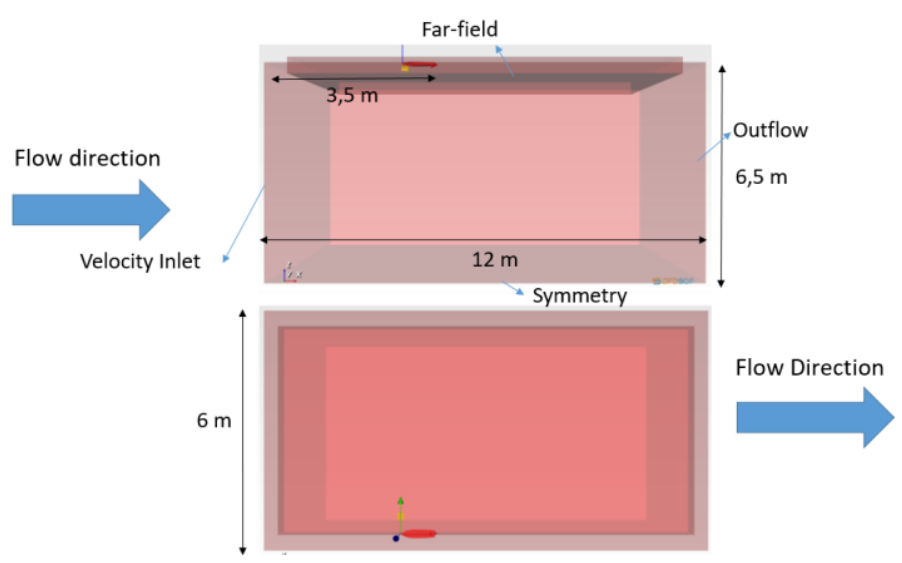

Figure 4 View of boxes

Next is to define each boundary. The inlet uses the inlet velocity type. The speed inputted follows the test speed of the ship. The outlet uses the outflow type. The outflow speed follows the ship's test speed. For faces with symmetry type, the boundary condition is symmetrical. The faces of the boundary type use a far field, which is suitable for 
compressible fluids (air). For the fluid flow in the simulation to be constant, it is necessary to adjust the initial conditions where the initial velocity is inputted based on the speed of the ship in the x-direction. In this setting, the water box is targeted for patching and is defined as water fluid, and the value is set to one.

The simulation is performed with a physical time of 5 seconds, a time-step (delta $t$ ) of $1 \mathrm{e}-4$, and a maximum courant number of one. The calculation saved every 0.1 seconds of computation time. Within 5 seconds, it is expected that the resistance value graph will approach a steady phase. This study is conducted with a transient model, in which the value of the resistance changes with time. The turbulence model used is RANS (Reynoldsaveraged-Navier-Strokes), with the k- $\omega$ SST model.

$$
\begin{gathered}
\frac{\partial u}{\partial x}+\frac{\partial v}{\partial y}=0 \\
\rho \frac{D}{D t}(u)=\rho g_{x}-\frac{\partial P}{\partial x}+\mu \nabla^{2}(u) \\
\rho \frac{D}{D t}(v)=\rho g_{y}-\frac{\partial P}{\partial y}+\mu \nabla^{2}(v) \\
\rho \frac{D}{D t}(w)=\rho g_{z}-\frac{\partial P}{\partial z}+\mu \nabla^{2}(w)
\end{gathered}
$$

This model is used because RANS focuses on the mean flow and the effects of the flow properties. This model does not focus on details on turbulent fluctuations; as such, it is sufficient only with time-averaged flow properties such as average velocity, pressure, etc. (Taha, 2005). Because the simulation is performed in two phases (water and air), the multiphase volume of fluid (VOF) option is used. Phase 1 is defined as water fluid with a density of $997.13 \mathrm{~kg} / \mathrm{m}^{3}$ and a dynamic viscosity of $8.91 \mathrm{e}-4$ Pa.s. Phase 2 is defined as a water fluid with a density of $1,225 \mathrm{~kg} / \mathrm{m}^{3}$ and a dynamic viscosity of $1.79 \mathrm{e}-5$ Pa.s.

ParaView is used to visualize the simulation results and calculate the value of ship resistance. After the simulation is complete, the ship and foil stern can be visualized with various options, such as pressure and alpha phase. To calculate the resistance, it is necessary to calculate the normal force in the x-direction by using the generate surfaces normal function. Subsequently, the pressure results obtained from the simulation are multiplied by the magnitude of the normal force in the $\mathrm{x}$-direction and are then integrated.

\subsection{Grid Independency Test}

The independence test is a test that measures the sensitivity of the mesh model system to the simulation results for various numbers of meshes such that we obtain the right amount of meshes for efficient computation time and high-quality results. The design used for the independence test on CFDSOF and the experimental data are sourced from previous research using a towing test in which the ship is driven by external propulsion connected to the data capture device of the ship (Syahrudin et al., 2020). It can be concluded that the most appropriate mesh count is $\pm 350,000$ with a computation time of 24-25 hours.

Table 1 Grid independency test results

\begin{tabular}{crcr}
\hline $\begin{array}{c}\text { Number } \\
\text { of Mesh }\end{array}$ & Simulation & Experiment & \multicolumn{1}{c}{ Error } \\
\hline \pm 150.000 & $8 \mathrm{~N}$ & $4.6 \mathrm{~N}$ & $73.91 \%$ \\
\pm 250.000 & $6.84 \mathrm{~N}$ & $4.6 \mathrm{~N}$ & $48.69 \%$ \\
\pm 350.000 & $5 \mathrm{~N}$ & $4.6 \mathrm{~N}$ & $8.69 \%$ \\
\pm 450.000 & $10.6 \mathrm{~N}$ & $4.6 \mathrm{~N}$ & $130.43 \%$ \\
\hline
\end{tabular}


CFDSOF was used to measure the water surface level on the hull surface and the ship resistance, and the numerical results were then compared with the experimental results in the literature. The results show similar trends for both methods (CCIT Group Indonesia, n.d.). Figure 5 presents a comparison of experiments and simulations using CFDSOF. To ensure the validity of the results from CFDSOF, an additional validation using other commercial software has been performed using a previous study (Budiyanto et al., 2020a). The comparison results show good agreement and indicate that the setup is accurate and can be used in vessels with a stern foil. The data used to validate the software setup is the ship resistance data. This comparison was performed on ships with working conditions in the Froude number range of 0.58-0.76 and a ship model without a stern foil.

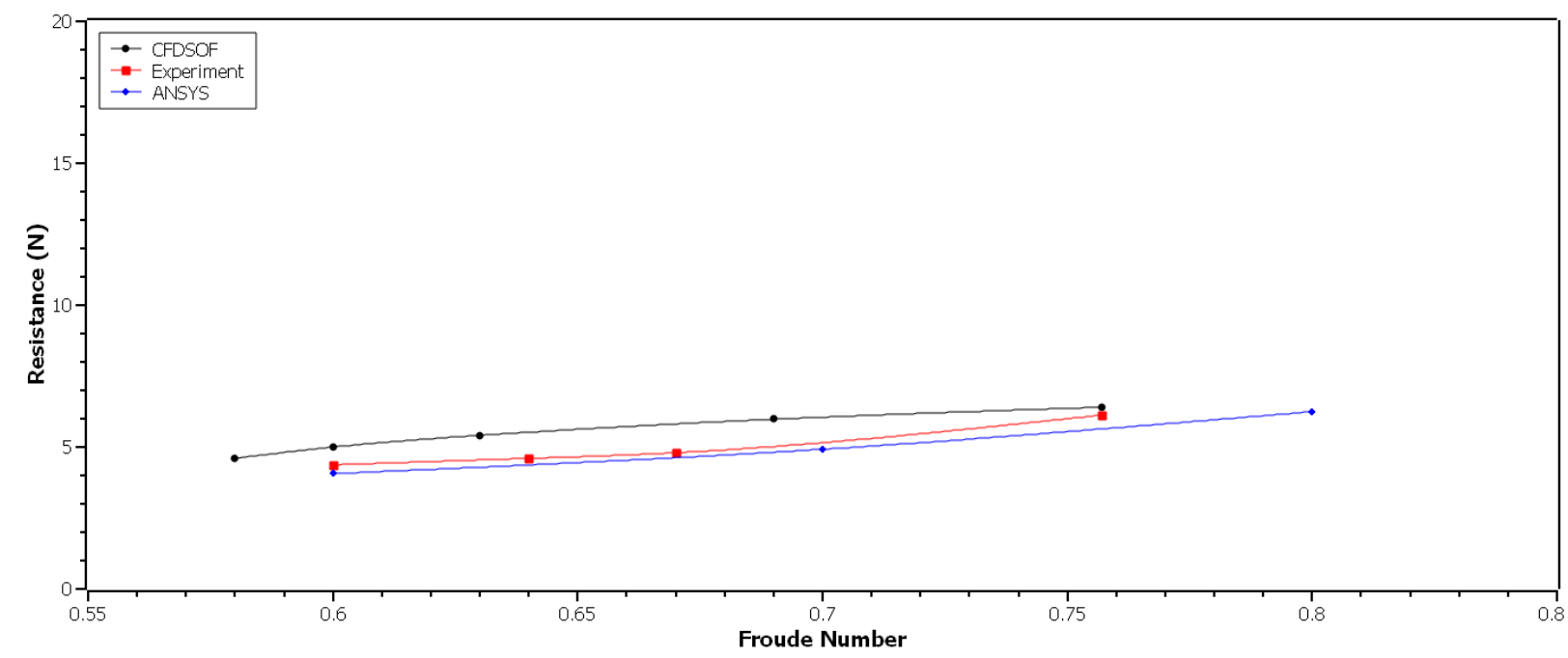

Figure 5 Validation of ship resistance using experiment and simulation methods

\section{Results and Discussion}

From Figure 6, it can be seen that using a stern foil is effective for reducing ship resistance by up to $26 \%$. The smallest reduction in drag, which was $9 \%$, occurred at an average speed of $2.3 \mathrm{~m} / \mathrm{s}$, at the lowest angle of attack of $5^{\circ}$. In contrast, the largest reduction in drag, $26 \%$, occurred at an average speed of $1.57 \mathrm{~m} / \mathrm{s}$, with $2^{\circ}$ as the largest angle of attack. These occurred because of the submergence factor: as the speed increases, the lift force increases, such that as the speed increases, the foil stern is closer to the surface of the water. The closer the foil stern is to the water surface, the smaller the lift force produced because the mass of fluid passing through the hydrofoil is smaller. It can be seen from the results that for each configuration of the angle of attack, from a speed of $1.57 \mathrm{~m} / \mathrm{s}$ to $2.3 \mathrm{~m} / \mathrm{s}$, the drag reduction trend grows smaller. A $2^{\circ}$ angle of attack configuration is the most optimal configuration based on these data, with the reduction in resistance ranging from $18 \%$ to $-26 \%$. This occurs because the lift coefficient is higher in the NACA 4412 profile, and consequently, the resulting thrust force is greater and drag reduction is optimal. While the lift coefficient is higher than $2^{\circ}$ in the $5^{\circ}$ angle of attack configuration, the drag coefficient at $5^{\circ}$ is greater than $2^{\circ}$. This can be deduced from the L/D (Lift to drag ratio), which is the ratio of lift to resistance. The higher the $\mathrm{L} / \mathrm{D}$ ratio, the smaller the drag. This result is consistent with the results from a previous study (Murdianto et al., 2020).

In Figure 7, the L/D ratio exhibits a downward trend in each configuration of the angle of attack plotted as a function of the Froude number. This could be because the higher the speed of the ship, the greater the resistance. The resistance on the ship (friction or wave resistance) will dominate the total resistance because basically, the resistance generated by 
the stern foil tends to be small. Although lift increases with increasing speed because of the dominance of the resistance of the ship, the comparison in L/D grows larger.

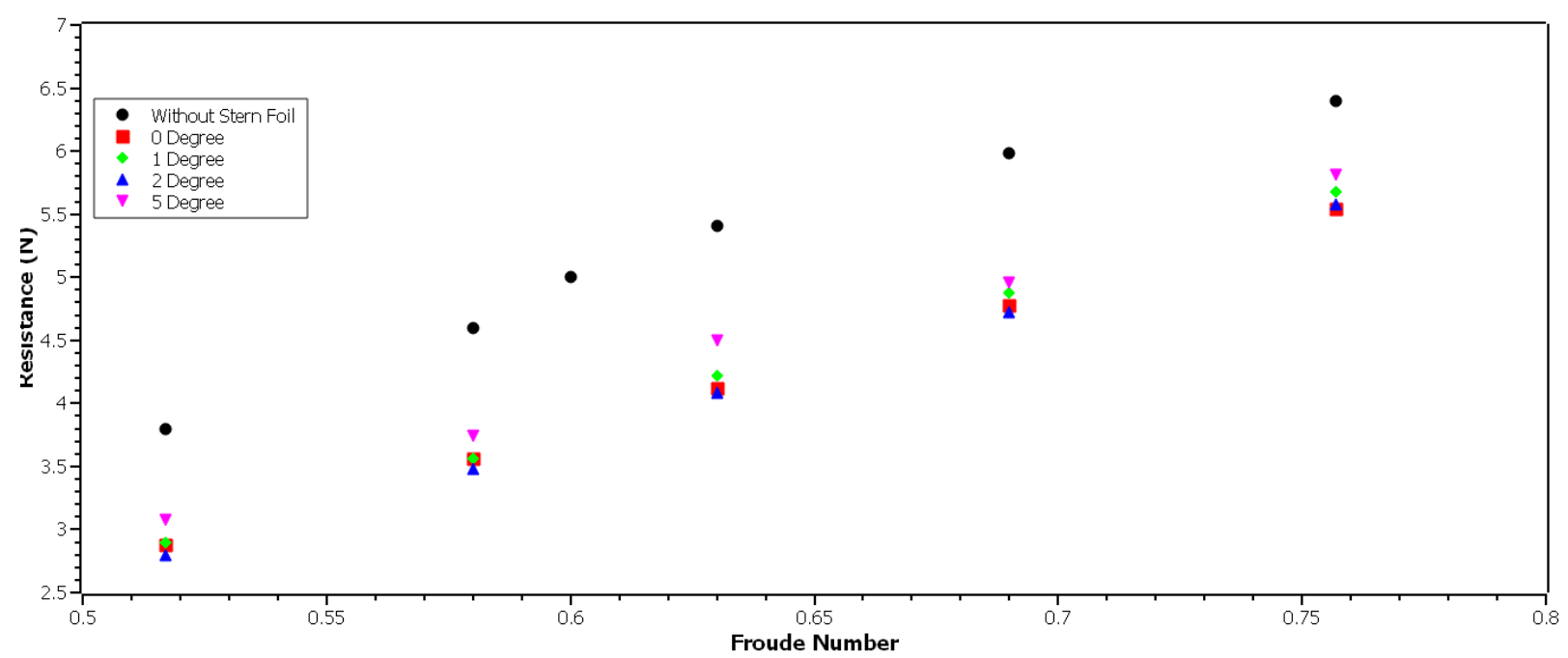

Figure 6 Effectiveness of the angle of attack of stern foil application

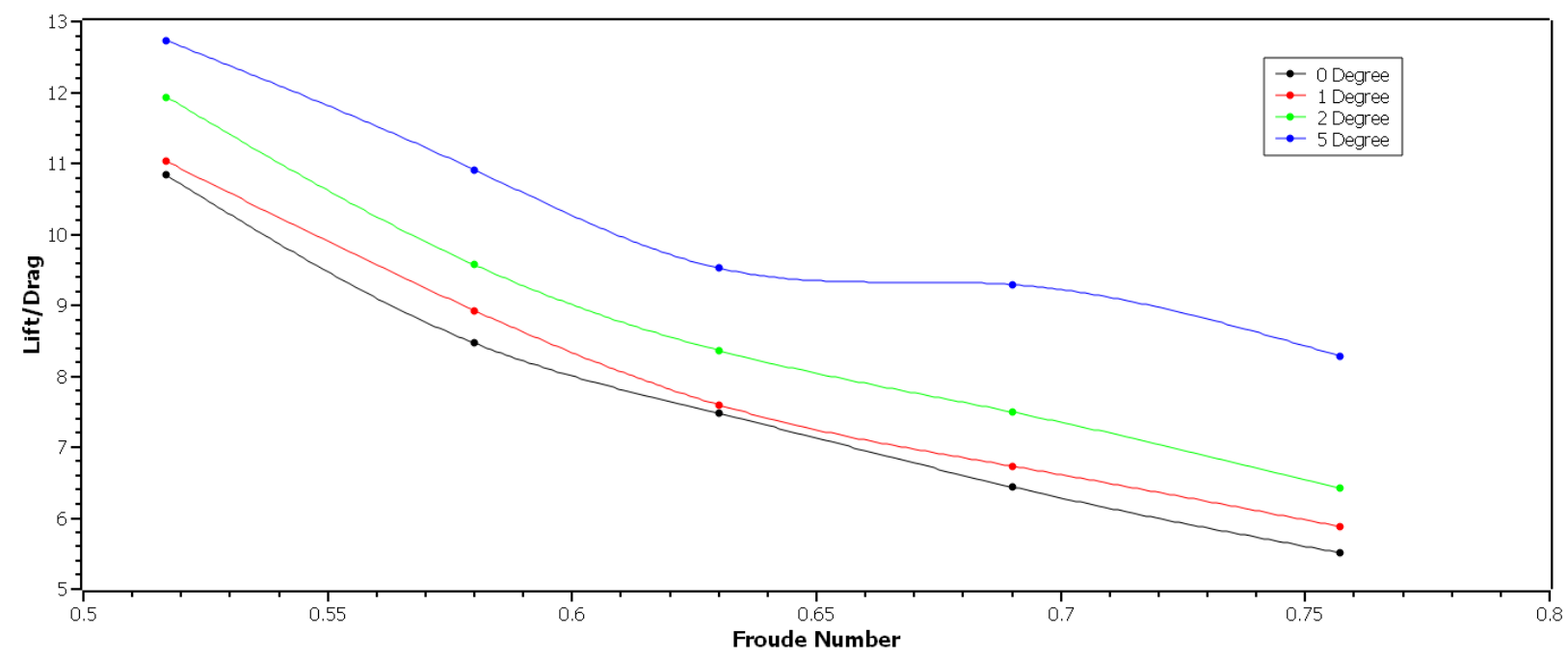

Figure 7 Lift to drag ratio of stern foil application

Figure 8 presents the velocity contour comparison for stern foil AOA 2 with a speed of $1.57 \mathrm{~m} / \mathrm{s}$ and without the stern foil.

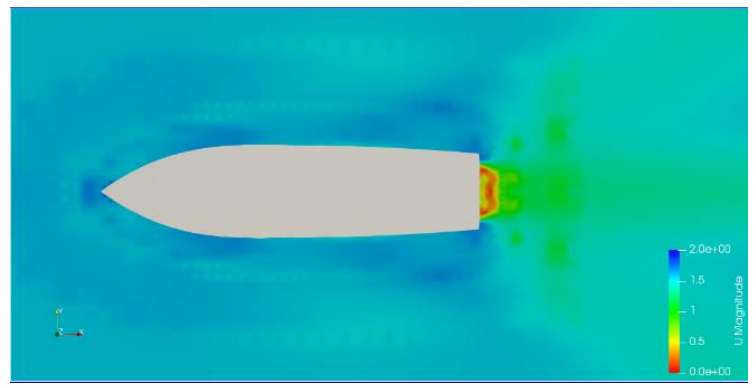

(a)

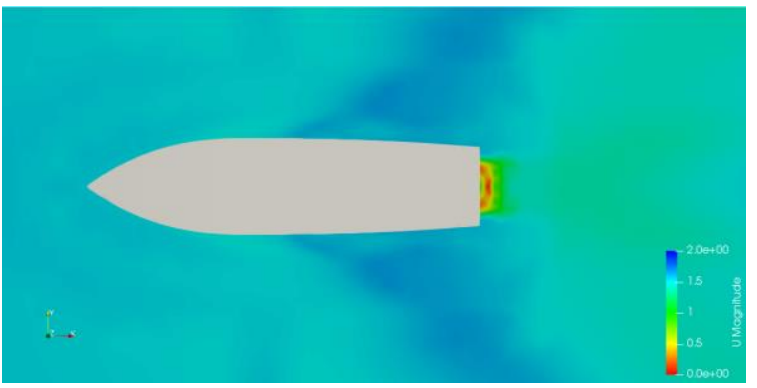

(b)

Figure 8 Speed contour at $1.57 \mathrm{~m} / \mathrm{s}$ : (a) with a $2^{\circ}$ stern foil; (b) without stern foil 
The occurrence of turbulence is related to the Reynolds number theory: the higher the speed, the greater the Reynolds number (Vellinga, 2009). Further, the higher the angle of attack, the greater the Reynolds number. Thus, the speed of the ship and the stern foil attack angle are crucial for turbulence. Figure 9 presents the velocity contour of the stern foil.

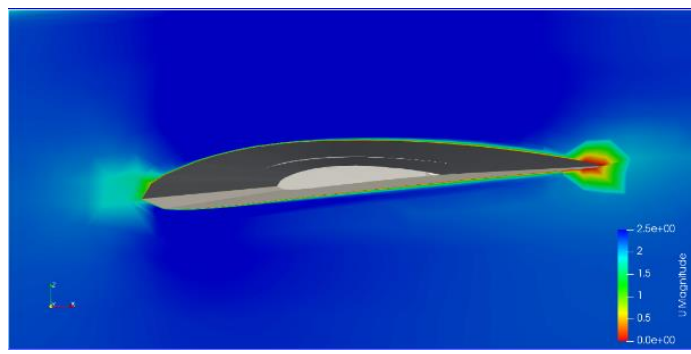

(a)

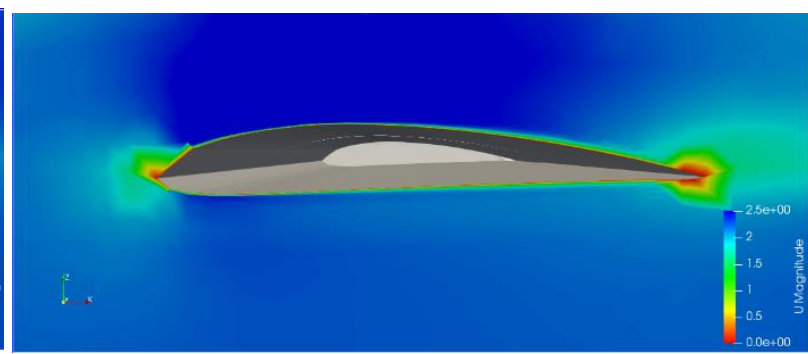

(b)

Figure 9 Speed contour at $2.3 \mathrm{~m} / \mathrm{s}$ : (a) $1^{\circ}$ stern foil; (b) $5^{\circ}$ stern foil

Figure 10 presents the decrease in resistance caused by using a stern foil, with each stern foil configuration at each speed represented by a Froude number compared to ships without a stern foil. The greater the percentage, the greater the reduction in resistance. From the graph in Figure 10, a $2^{\circ}$ stern foil configuration operating at a speed of $1.57 \mathrm{~m} / \mathrm{s}$ is the most effective configuration for reducing ship resistance, at a $26 \%$ reduction. However, a $5^{\circ}$ stern foil configuration operating at a speed of $2.3 \mathrm{~m} / \mathrm{s}$ generated the least resistance reduction, 9\%. Therefore, the use of a stern foil is effective for reducing resistance on ships by $9 \%-26 \%$.

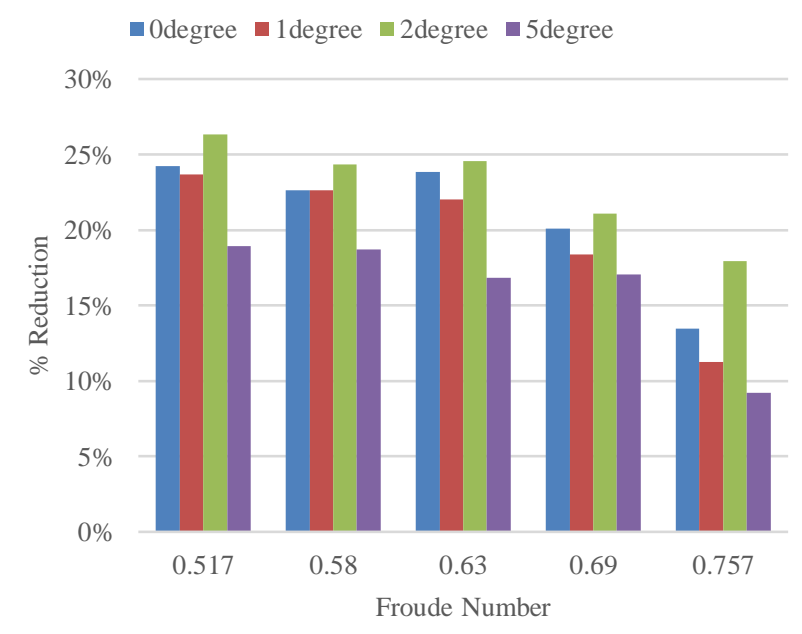

Figure 10 Comparison of ship resistance reduction by stern foil application

Figure 11 presents verification of the simulation in this study. CFD model verification and validation are an important part of the post-processing in this research. CFD verification looks for errors that occur during the implementation of the model by checking the convergence of iterations (monitoring the residue results), checking consistency and grid convergence, and comparing the computational results with analytical solutions. CFD validation checks the model to determine whether it matches real conditions by comparing the computation results with the experimental results. The primary purpose of this verification and validation is to obtain the best and most acceptable results. 


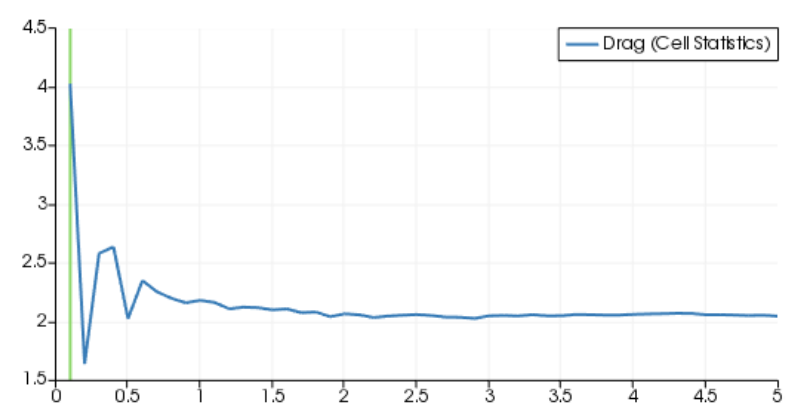

Figure 11 Resistance vs. time graph on ParaView for a $2^{\circ}$ stern foil ship at a speed of $1.93 \mathrm{~m} / \mathrm{s}$

\section{Conclusions}

Simulations using the CFD method in CFDSOF were performed on patrol boats using stern foil with various angles of attack at several speeds. Based on research data and analysis, it can be concluded that simulations using the CFD method can be performed using CFDSOF software to calculate the amount of resistance on a ship and predict other results such as lift, velocity contours, and wave patterns at high speeds or varied angles of attack of the same setup. The setup starts with a grid independence test that determines the number of meshes to be $\pm 350,000$. To achieve that number of meshes, using the ship geometry, stern foil, refinement box, and water box, the refinement parameter used on the ship is five, and seven for the stern foil. The simulation is then set to multiphase, with SST $\mathrm{k}-\omega$ as the turbulence model. The boundary condition on $\mathrm{x}$ negative is an inlet; $\mathrm{x}$ positive is an outlet; y positive, $y$ negative, and $\mathrm{z}$ negative are symmetry; $\mathrm{z}$ positive is the far field boundary. In this study, a ship with a $2^{\circ}$ stern foil configuration operating at a speed of 1.57 $\mathrm{m} / \mathrm{s}$ had the most effective had the most effective reduction in drag, which is $26 \%$. In contrast, a ship with a $5^{\circ}$ stern foil configuration operating at a speed of $2.3 \mathrm{~m} / \mathrm{s}$ experienced the least resistance reduction of $9 \%$. However, the use of foil sterns is effective for reducing resistance on ships by $9 \%-26 \%$.

\section{Acknowledgements}

The author is very grateful to the Research Assignment for the 2020 Fiscal Year, Ministry of Research and Technology Republic of Indonesia/National Research and Innovation Agency (KEMENRISTEK/BRIN) through the Directorate Research and Development (DRPM) Universitas Indonesia. Main contract number: 8/E1/KP.PTNBH/2020, with extension number: 255/PKS/R/UI/2020 and UI contract number: NKB-509/UN2.RST/HKP.05.00/2020.

\section{References}

Afriansyah, S.Y., Budiarto, U., Manik, P., 2019. Analysis of Addition of Hull Vane with NACA 4412 Foil Type to Obstacle and Lifting Force on a 15 Meter Pilot Boat with Variations in Angle of Attack and Depth of Foil using the CFD Method. Jurnal Teknik Perkapalan, Volume 7(1), pp. 1-10

Agustian, R.B., Chrismianto, D., Zakki, A.F., 2017. Analysis of Swept Fully Submerged Foil Angle Change Against Lift \& Resistance on 15 Meter Pilot Boat. Jurnal Teknik Perkapalan, Volume 5(2), pp. 421-430

Assidiq, R., Hadi, E.S., Manik, P., 2017. Analysis of the Effect of NACA 2412 Type Hull Vane with a $0^{\circ}$ Angle of Obstacle and Seakeeping on a 750 DWT Pioneer Ship with Variations in the Number and Position of the Foil Hull Vane using the CFD Method. Teknik 
Perkapalan, Volume 5(2), pp. 421-430

Azis, D.N., Chrismianto, D., Adietya, B.A., 2017. Lifting Force and Resistance Analysis on Dihedral Surface Piercing Hydrofoil Catamaran using CFD (Computational Fluid Dynamic) Method. Jurnal Teknik Perkapalan, Volume 5(2), pp. 421-430

Bouckaert, B., Uithof, K., Moerke, N., Van Oossanen, P.G., 2016. Hull Vane ${ }^{\circledR}$ on 108m HollandClass OPVs: Effects on Fuel Consumption and Seakeeping, p. 12

Budiyanto, M.A., Murdianto, M.A., Syahrudin, M.F., 2020a. Study on the Resistance Reduction on High-Speed Vessel by Application of Stern Foil using CFD Simulation. CFD Letters, Volume 12(4), pp. 35-42

Budiyanto, M.A., Syahrudin, M.F., Murdianto, M.A., 2020b. Investigation of the Effectiveness of a Stern Foil on a Patrol Boat by Experiment and Simulation. Cogent Engineering, Volume 7(1), 1716925 pp. 1-17

CCIT Group Indonesia. (n.d.)., CFDSOF. PT. CCIT Group Indonesia

Dewi, F.P., 2017. Analysis of Stall NACA 23021 Phenomenon on Application Hydrofoil. Master's Thesis, Graduate Program, Institut Teknologi Sepuluh Nopember

Hagemeister, N., Uithof, K., Bouckaert, B., Mikelic, A., 2017. HULL VANE ® VERSUS LENGTHENING - A Comparison between Four Alternatives for a $61 \mathrm{~m}$ OPV. FAST Conference 2017, pp. 1-11

Lubis, B.P.A., Manik, P., Adietya, B.A., 2018. Analysis of the Effect of the Addition of Grothues Spoilers with Geometry Variations in the Shaped of NACA Foil on a 750 DWT Pioneer Ship on Resistance and Ship Wake Value using the CFD Method. Jurnal Teknik Perkapalan, Volume 6(4), pp. 1-10

Murdianto, M.A., Budiyanto, M.A., Syahrudin, M.F., 2020. Application of Stern Foil on Full Draft Patrol Vessel at High-Speed Condition using Computational Fluid Dynamics (CFD) Method. In: AIP Conference Proceedings, 2255(1), 020023

Nugroho, A.S., Hadi, E.S., Manik, P., 2017. Analysis of the Effect of the Addition of Grothues Spoilers with Geometry Variations in the Shaped of NACA Foil on a 750 DWT Pioneer Ship on Resistance and Ship Wake Value using the CFD Method. Teknik Perkapalan, Volme 5(2), pp. 421-430

Samuel., Iqbal, M., Utama, I.K.A.P., 2015. An Investigation into the Resistance Components of Converting a Traditional Monohull Fishing Vessel into Catamaran Form. International Journal of Technology, Volume 6(3), pp. 432-441

Siagian, J., Manik, P., Hadi, E. S., 2018. Analysis of the Effect of the Addition of NACA 64098 Grothues Spoilers with Variations in the Number of Spoilers on the 750 DWT Pioneer Ship on the Barriers and Wake Value of the Ship using the CFD Method. Jurnal Teknik Perkapalan, Volume 6(4), pp. 11-20

Slamet, A.S., Suastika, K., 2012. Experimental Study of the Effect of Positioning of Supporting Hydrofoil on Ship Resistance. Jurnal Teknik ITS, Volume 1(1), pp. 1-4

Suastika, K., Hidayat, A., Riyadi, S., 2017. Effects of the Application of a Stern Foil on Ship Resistance: A Case Study of an Orela Crew Boat. International Journal of Technology, Volume 8(7), pp. 1266-1275

Suryadi, A., 2016. Analysis of Hydrofoil Attack Angle of the Lift Force of a Trimaran Hydrofoil Ship Using the Computational Fluid Dynamics (Cfd) Method. Undergraduate thesis, Institut Teknology Sepuluh Nopember, Indonesia.

Syahrudin, M.F., Budiyanto, M.A., Murdianto, M.A., 2020. Analysis of the Use of Stern Foil on the High-Speed Patrol Boat on Full Draft Condition. Evergreen, Volume 7(2), pp. 262267

Taha, T.R., 2005. An Introduction to Parallel Computational Fluid Dynamics. IEEE Concurrency. Volume 6(4), p. 78 
Uithof, K., Bouckaert, B., Van Oossanen, P.G., Moerke, N., Hull Vane, B.V., 2016a. The Effects of the Hull Vane on Ship Motions of Ferries and Ropax Vessels. In: Royal Institution of Naval Architects - Design and Operation of Ferries and Ro-Pax Vessels 2016, May, 2526, London, UK

Uithof, K., Hagemeister, N., Bouckaert, B., Van Oossanen, P.G., Moerke, N., Hull Vane, B.V., 2016b. A Systematic Comparison of the Influence of the Hull Vane®, Interceptors, Trim Wedges, and Ballasting on the Performance of the 50M Amecrc Series \#13 Patrol Vessel. In: Royal Institution of Naval Architects-Warship 2016: Advanced Technologies in Naval Design, Construction, and Operation, June, 15-16, Bath, UK

Vellinga, R. 2009. Hydrofoils Design Built Fly. Paperback: Illustrated

Yanuar., Putra, M.S.G., Akbar, M., Alief, M., Fatimatuzzahra., 2020. Numerical Study on Influence of Hydrofoil Clearance Towards Total Drag Reduction on Winged Air Induction Pipe for Air Lubrication. International Journal of Technology, Volume 11(1), pp. 91-99 